\title{
Autun (Saône-et-Loire). Étude archéologique du cloître canonial de Saint-Nazaire
}

\section{Sylvie Balcon-Berry et Walter Berry}

\section{(2) OpenEdition}

1 Journals

\section{Édition électronique}

URL : https://journals.openedition.org/cem/864

DOI : $10.4000 /$ cem.864

ISSN : 1954-3093

Éditeur

Centre d'études médiévales Saint-Germain d'Auxerre

\section{Édition imprimée}

Date de publication : 15 août 2004

ISSN : 1623-5770

\section{Référence électronique}

Sylvie Balcon-Berry et Walter Berry, « Autun (Saône-et-Loire). Étude archéologique du cloître canonial de Saint-Nazaire », Bulletin du centre d'études médiévales d'Auxerre | BUCEMA [En ligne], 8 | 2004, mis en ligne le 13 décembre 2006, consulté le 22 septembre 2022. URL : http://journals.openedition.org/cem/ 864 ; DOl : https://doi.org/10.4000/cem.864

Ce document a été généré automatiquement le 22 septembre 2022.

\section{c) (i) (2)}

Creative Commons - Attribution - Pas d'Utilisation Commerciale - Partage dans les Mêmes Conditions 4.0 International - CC BY-NC-SA 4.0

https://creativecommons.org/licenses/by-nc-sa/4.0/ 


\title{
Autun (Saône-et-Loire). Étude archéologique du cloître canonial de Saint-Nazaire
}

\author{
Sylvie Balcon-Berry et Walter Berry
}

1 L'année 2003, qui marquait à la fois les 20 ans de recherches entreprises à l'initiative de Christian Sapin et la fin des investigations de terrain, fut très fructueuse. En effet, outre une étude complémentaire de la zone occidentale du cloître, riche en découvertes, la galerie orientale qui a particulièrement retenu notre attention, recelait des informations capitales pour comprendre de façon plus précise l'histoire du site.

2 À l'est, justement, d'autres parties d'une vaste habitation de l'Antiquité tardive, mise partiellement au jour en 2001-2002, ont été retrouvées. Les nouvelles observations tendent à confirmer que le bâtiment, doté d'un portique occidental desservant des salles situées à l'est, aurait été élevé au cours du III ${ }^{\mathrm{e}}$ siècle puis restructuré au IV ${ }^{\mathrm{e}}$ siècle suite à un incendie. L'édifice comprenait alors une grande salle (découverte dans la "salle capitulaire") au sol en mortier de tuileau particulièrement soigné. Cette demeure que l'on peut vraisemblablement tenir pour la domus ecclesiae a été totalement remaniée à la période mérovingienne, ce dont témoignent des murs en pierre sèche qui lui ont été associés. C'est apparemment aussi l'époque de l'installation d'une tombe mise au jour dans la galerie orientale, mais qui, au contraire de la majorité des autres sépultures fouillées antérieurement dans le préau, est orientée est-ouest et non nord-sud. Cette inhumation est plus ancienne qu'une grande bâtisse en bois, elle-même précédant de peu l'installation en dur du premier cloître (milieu IX ${ }^{\mathrm{e}}$ siècle, sous l'évêque Jonas). La présence de sépultures mérovingiennes intra-muros ainsi que l'ampleur du bâtiment en bois orienté nord-sud méritent d'être soulignées. En ce qui concerne ce dernier, il pourrait s'agir des vestiges d'un édifice faisant partie d'une toute première installation claustrale, mais, pour l'heure, la prudence est de mise.

Du cloitre carolingien, des vestiges de sols et surtout le mur oriental (conservé sur une élévation de plus de trois mètres, ce qui est tout à fait remarquable) ont été identifiés. Cette paroi se singularise par la présence d'un arc à joints rubanés, dont la facture très 
soignée, conduit à le dater du milieu du IX ${ }^{\mathrm{e}}$ siècle. Malheureusement, comme dans la galerie sud, le mur ouest a été presque entièrement récupéré au $\mathrm{XVI}^{\mathrm{e}}$ siècle. La tranchée de récupération a toutefois épargné des vestiges de ce qui doit correspondre à des pilastres et des fondations de contreforts. Ces éléments lacunaires remontent probablement au $\mathrm{XI}^{\mathrm{e}}$ siècle, époque d'une grande restructuration de la galerie avec voûtement et mise en place d'un dallage précédé d'un décaissement. L'opération du XVI siècle a d'autre part pris soin de ménager une base de colonnette du XII ${ }^{\mathrm{e}}$ siècle, témoin d'un remodelage de l'élévation de la galerie. Cet élément doit être lu en parallèle avec le chapiteau en place dans l'extrémité sud-ouest de la galerie et avec une autre base, plus imposante, trouvée légèrement plus à l'ouest dans le "passage" (espace sis immédiatement au nord de la galerie orientale dans son état actuel). La présence de ces deux bases laisse penser qu'un portail monumental fut créé au XII ${ }^{e}$ siècle pour magnifier le centre de la galerie orientale. La phase du XII ${ }^{e}$ siècle a concerné aussi la réfection du dallage. Puis, au $\mathrm{XV}^{\mathrm{e}}$ siècle, une grande campagne de transformation a consisté en une reprise de culées d'arcs-boutants installées à l'ouest au XIV siècle. Ces derniers éléments, totalement dégagés de l'ancien mur occidental, ont été transformés en supports destinés à recevoir les retombées des voûtes d'arêtes ainsi que les arcades occidentales, nouvellement aménagées. Le revoûtement du $\mathrm{XV}^{\mathrm{e}}$ siècle n'a toutefois pas affecté l'extrémité méridionale de la galerie dont le remodelage qui a englobé une voûte du XII siècle, n'est intervenu qu'au XVI ${ }^{\mathrm{e}}$ siècle, époque d'une transformation consécutive à l'abandon de la fonction canoniale de la cour accolée au sud de la cathédrale Saint-Nazaire.

4 Aux XVII ${ }^{\mathrm{e}}$-XVIII ${ }^{\mathrm{e}}$ siècles, l'aile orientale a accueilli des activités artisanales dont témoigne une succession de fours installés par un ou plusieurs forgerons. La fouille de ces niveaux a conduit à la découverte de fragments de grilles du XII ${ }^{e}$ et $d u X V^{e}$ siècle provenant de Saint-Nazaire ou de Saint-Lazare.

5 Des interventions très ponctuelles ont permis de confirmer plusieurs hypothèses, avancées antérieurement, quant à l'évolution générale du cloître. Ainsi, dans l'angle sud-ouest, les découvertes s'accordent en grande partie avec celles faites plus à l'est. En effet, un décaissement du $\mathrm{XI}^{\mathrm{e}}$ siècle, préalable à la mise en place d'un dallage et qui a entamé les sols carolingiens, a été noté. Une base datant elle aussi du $\mathrm{XI}^{\mathrm{e}}$ siècle a été découverte. Située dans l'angle sud-ouest, elle a été englobée dans les reprises du $\mathrm{XV}^{\mathrm{e}}$ siècle du mur sud (autrement dit le mur nord du réfectoire). Un négatif qui devait recevoir un socle surmonté d'un pilastre, installés là aussi au $\mathrm{XI}^{e}$ siècle, a en outre été mis au jour. D'autres perturbations à rattacher au $\mathrm{XV}^{\mathrm{e}}$ siècle ont par ailleurs été observées.

Quant à la petite opération menée devant le cellier, là où un sondage a été ouvert en 2000 , elle a permis la découverte de traces d'un mur de soutènement antique faisant partie, selon toute probabilité, d'un vaste système de terrasses, aménagé pour occuper de façon rationnelle la ville haute. De fait, une hypothèse proposée de longue date se vérifie, et si les installations carolingiennes ont entraîné un dérasement de l'espace pour former la surface plane du futur préau, elles ont su tirer profit de certaines de ces terrasses antiques en venant partiellement s'installer dessus et en en récupérant les blocs.

7 Toutes ces données, recueillies jusqu'à très récemment, sont sujettes à caution et seront éprouvées en 2004-2005, à l'occasion de la rédaction d'un rapport de synthèse puis, on l'espère, d'une publication. Cette dernière fera état des recherches entreprises 
sur le site depuis 1983 concernant tant l'enfoui associé aux élévations que le mobilier archéologique particulièrement abondant sur ce site ${ }^{1}$.

\section{NOTES}

1.- Les étés 2004 et 2005 seront presque entièrement consacrés à l'étude d'une grande partie de ce mobilier à laquelle participeront des étudiants de l'Université de Paris IVSorbonne dans le cadre d'un stage.

INDEX

Mots-clés : Nazaire (saint), Saint-Nazaire d'Autun, cloître

Index géographique : France/Autun 